\title{
INTERACTION IN THE COURSE OF ECONOMIC CRIME INVESTIGATION: THEORETICAL BACKGROUND
}

\author{
Tetyana Kaganovska ${ }^{1}$, Oleksandr Holovko ${ }^{2}$, Maksym Danshyn $^{3}$ \\ V. Karazin Kharkiv National University, Ukraine
}

\begin{abstract}
The aim of this article is to define the factors, its peculiarities and determinant connection related to the efficient interaction of operative units with other structures in the course of economic crime investigation. Research subject theoretical background of interaction in the course of the economic crime. Methodological research is based on the dialectical method of scientific cognition and derived general methods: analysis, analogy, induction etc. Research results demonstrated that specific factors of fact-finding procedure in the course of the pre-trial investigation and peculiarities of criminological characteristics of economic crimes considerably affect the nature and areas of law enforcement agencies interaction within the pre-trial investigation of economic crimes as they determine the specifictasks and methodology of its accomplishment. Practical value. Many recent papers have been dedicated to further elaboration of the abovementioned concepts with consideration of large-scale transformations taking place in the criminal process. Separate features of the fact-finding process in the course of crime investigation are noted along with typical counteracting measures used to condition (with the aim to neutralize) the application of chosen criminalistic methods and operative-search activities, relevant forms of investigative process organization etc. Value/originality. Features and peculiarities of investigation as a fact-finding practical activity are identified, which is crucial for understanding the roles of different subjects in this process who apply numerous cognitive methods in the course of the economic crimes investigation.
\end{abstract}

Key words: interaction, investigation, economic crimes, factors.

JEL Classification: C31, E71

\section{Problem statement}

Criminalistic research conducted in Eastern Europe currently tends to focus steadily on ensuring the efficient interaction between operative units and other structures in the course of crime investigation. Still, very little attention is paid to factors conditioning the necessity of such interaction. Of the utmost importance is to conduct a thorough study of the abovementioned process in the area of economic crimes - a lot of issues are still defined as controversial. At the same time, criminalistic research carried out by Ukrainian experts allowed to accumulate considerable theoretical blocks with the opportunity to determine the factors which directly influence the process of selecting optimal formats ofinteraction between the abovementioned structures in the course of economic crimes investigation.

\section{Analysis of the latest publications}

A valuable contribution to the research of the stated phenomenon has been made by Ukrainian and foreign scholars including A. Volobuiev, O. Holovko, M. Danshyn, O. Zayets, A. Ishchenko, T. Kaganovska, O. Korystin, I. Luzgin, V. Maliarova, H. Matusovskyi, S. Pavlenko, M. Pohoretskyi, V. Sevruk, R. Stepaniuk, O. Tsilmak, S. Cherniavskyi. The aim of this article is to define the factors, its peculiarities and determinant connection related to the efficient interaction of operative units with other structures in the course of economic crime investigation.

\section{The main material}

At the current stage of its evolution, human civilization is affected deeply with global integration processes, which trigger the transformations of economic, social, cultural, informational interaction mechanisms it inevitably stimulates the reforming dynamics in all areas (Pavlenko, 2017).

Seemingly, the factors which condition the involvement and interaction of different units of law

\footnotetext{
Corresponding author:

${ }^{1}$ Law Faculty, V. Karazin Kharkiv National University.

E-mail: tekaganovskaya@gmail.com

${ }^{2}$ Legal Disciplines Department, Law Faculty, V. Karazin Kharkiv National University.

E-mail: golovkoom1967@ukr.net

${ }^{3}$ Legal Disciplines Department, Law Faculty, V. Karazin Kharkiv National University.

E-mail: crime_science@ukr.net
} 
enforcement agencies and other bodies in the course of crime investigation already emerge in the fact-finding process itself. One of the first researchers who analysed the features of the fact-finding process within the pretrial investigation of crimes which influence the selection and application of cognitive methods was I. Luzgin. Thus, he distinguished the following specific features of investigation as a fact-finding practical activity:

1) dependence of investigator's cognitive activity from its subject presented as a crime - socially dangerous act (stipulates the application of coercive measures to prevent any impediments of obstructions for the investigation, establishing favourable conditions for its completion);

2 ) as any crime is committed by human, psychological factors are defined as primary in the investigative process - psychological peculiarities of a criminal (on the basis of this factor, investigative tactical techniques are developed along with scientifically-grounded recommendations for the investigator concerning his/her correct behaviour and response in multiple situations, study of cognitive capacity etc.);

3) crime as intentional act characterizing the person's behaviour in the surrounding environment marks it with certain "traces" not only by affecting other persons conscience but also transforming the material objects (the nature of these traces requires special equipment and techniques to be applied during the investigation with reference to specified scientific data);

4) fact-finding activity as a part of investigation is tightly connected with the proving (fixation of accumulated information according to applicable procedures with the aim to ensure that this information will be thoroughly studied and evaluated by all the parties to the criminal process and the court), but its subject is still an extended notion as it comprises apart from the fact in proof also the circumstances, which do not constitute its elements including the operative data of tactical significance (Luzgin, 1969).

Provisions on the fact-finding process peculiarities, elaborated by I. Luzgin, are important for the understanding of the role of different subjects in this process (subjects who apply different cognitive methods). The author interprets these methods as a certain set of interrelated and mutually conditioned practical cognitive operations, which are tightly connected with cognitive means (tools). It is underlined that the specificity of cognitive methods in the course of an investigation is defined, firstly, with the influence of standards and requirements set by criminal legislation and relevant by-laws regulating the procedure of investigation conduct. Secondly, the nature of investigative means and techniques is considerably affected by the subject of the fact-finding process itself presented in the form of the criminal act. Thirdly, cognitive methods are influenced by the nature of the fact-finding practical activity - investigative, operative- search, judicial (Luzgin, 1969). The author is pointing out how important is the use of studied methods and formulation of certain conclusions in criminal cases. In this context, for example, experts consider the classification of versions as investigative, operativesearch, expert, judicial (Luzgin, 1969).

Current scientific papers elaborate on the abovementioned provisions with due consideration of conceptual transformations taking place in the criminal process. Thus, the following peculiarities of the factfinding process in the course of crime investigation are:

1. A past event is an object of the cognitive process. Crime as a fact is referred to events that have already happened (past event) and it is possible to identify the circumstances of required legal value only if certain traces are present. It means that there is always a certain time gap between the commission of the crime and its investigation. If we interpret the definition of crime traces in a more extended format, it will define any reflection of crime committed (material or ideal) in the surrounding environment. Traces are understood as all modifications, which are detected in the surrounding environment as a result of a socially dangerous act performed by the individual. But, as a rule, the crime is not fully reflected in the traces - only partially, which substantially impedes the fact-finding process.

2. Crime traces may resemble the traces of non-criminal act. It results in certain doubts and difficulties related to the identification of detected traces as criminal because any event - prior or after the crime commission - may be characterized with certain traces left. Moreover, in some cases, it is very hard to evaluate traces with consideration of possible event nature.

3. Crime investigation is always carried out in a specific environment (with existing or potential resistance). Crime is a socially dangerous act, the commission of which is subject to criminal liability (punishment). Criminals tend to avoid the prosecution in any possible way, using certain techniques and means to conceal it, obstructing the process of investigation. One of the most widely used ways is to destroy the traces, create an artificial environment after committing the crime, and falsify selected traces which leads to many problems for further evaluation.

4. The fact-finding process itself is presented in the form of proving. Crime investigation is carried out with the use of methods and means aimed at proof obtaining according to criminal procedure legislation (searchoperative activity). Laws regulate the procedure for its application, establish fixed terms of criminal proceedings. Requirements and instructions contained in criminal legislation limit the investigation period within a certain timeframe and set standard decisionmaking forms, which substantially affect the fact-finding process (Volobuiev, Danshyn, Ishchenko, etc. 2017).

Textbooks and reference materials have recently been focusing on differentiation of methods used to 
investigate criminal offenses. In particular, among the methods that are being developed or adapted in theoretical aspect, certain methods are presented, which are used directly by the investigator during the performance of investigative activities and methods, which in the course of investigation are used with involvement of specialist or expert (use of special knowledge - methods "borrowed" from other scientific branches). Separate group is composed of methods of operative-search activity which, if combined with criminalistic methods, are intended to eliminate all difficulties related to investigation, prevent any potential attempts to impede the investigation, identify all circumstances of the criminal offence, and collect relevant evidence (Volobuiev, Danshyn, Ishchenko, etc., 2017; Tsilmak, Korystin, Zayets, etc., 2017).

While investigating the economic crimes, which are presented as the object of the fact-finding process, investigative activities and relevant fact-finding methodology are considerably influenced by the peculiarities of these crimes reflected in its criminalistic characteristics. First of all, we should note that the definition of the economic crime itself contains different aspects - criminal-legal, criminological, criminalistic (Volobuiev, 2003). If interpreted through criminalistic aspect, economic crimes are characterized as an illegal lucrative activity performed by individuals with the use of legitimate business activity forms or relevant authorities on the abovementioned activity control (Matusovskyi, 1999). Their determining peculiarities are revealed in the following elements of criminalistic characteristics: the object of criminal intention, the identity of the perpetrator, traces - evidence sources, means of crime commission, techniques and methods of crime prevention.

\section{Features of economic crime subject}

Economic crime subject takes an important place in the system of its criminalistic characteristics as it substantially affects the means of crime commission and concealment (Cherniavskyi, 2009). The object of criminal intention in the area of business activity is often presented by financial assets in national or foreign currency (cashless form), securities, sometimes material values. Cashless financial assets ("bank money") are in fact data on available bank account assets. According to legislative acts adopted by the National Bank of Ukraine (NBU) cashless financial assets may be kept at current or deposit account.

Securities (equities, bonds, bills etc.) are used as financial tools, which validate the fact of certain right accrual. Its attractiveness as the objects of criminal intention is conditioned with the accrual of relevant ownership right which, in its turn, validates the obtaining of property or financial assets. Also, securities may be sold - therefore, it also is granted with the status of value measure. Its circulation is regulated by specialized legislation and by-laws.

Material values are usually chosen as the direct object of criminal intention in business activity in the form of certain commodity batches, which are illegally occupied by the fraudulent entrepreneur (fraudster) upon certain agreement, misleading the partner. Traces of these actions are foremost left in numerous accounting documents. Therefore, the conditions related to the object of criminal intention (economic crimes) and its reflection are crucial for the application of specific methods with the aim to detect these crimes and collect evidence.

Features of economic crime subjects. During the detection and investigation of economic crimes, it is necessary to take into account the typical features of its subjects. Scholars' analysis and criminal case materials prove that individuals from the mentioned category, as a rule, belong to upper middle class (so-called "white collars"):

- individual entrepreneur (natural person, performs activity without establishing the entity);

- founder (shareholder) of the entity;

- hired worker (manager) of the entity;

- hired expert (economist, accountant, engineerelectrician etc.);

- public official granted with control and regulatory authorities (Volobuiev, 2000).

In current conditions, shaped by a number of economic and political controversies, the voice of ethnic minorities is strengthening while some of them are involved in illegal economic activity (Sevruk, 2016).

The abovementioned individuals also involve qualified experts and specialists in their illegal activity if the latter possess considerable financial assets and certain social connections, which may potentially be used to obstruct the investigation. The typical feature of a criminal group organized by them - use of criminal "expertise" along with official position privileges and professional skills.

The abovementioned features of economic crime subjects require application by law enforcement of such crime detection methods, which would allow not only detecting the crime itself but also preventing possible resistance from the mentioned individuals to neutralize it sufficiently.

\section{Features of traces - evidence source}

Economic crimes are reflected (through traces left) in different objects. According to the statement expressed by S. Cherniavskyi, the list of objects, which maintain certain data related to the fact of crime, is relatively composed of six categories: 1) documents (written, graphic, photo-, video-, audio-, and electronic files); 2) items (stamps, clichés, blank templates, payment cards, equipment used to produce the means of access to bank accounts); 3) premises (warehouses, 
offices, residential space etc.);4) material values and commodities (movable and immovable property) and financial assets (cash and cashless forms including electronic bank transactions); 5) electronic media (system units, magnetic and laser disks etc.); 6) individuals' memory (Cherniavskyi, 2010).

Economic crimes are reflected first of all in accounting documents and records, registration books and regulatory acts related to business entity activity, bank documents etc. That is why all documents connected with economic crimes must be taken into consideration as one of the categories of criminalistic trace theory. Individual memory is also of high significance but in many cases only if collected jointly with documents. It is much harder to detect economic crimes with the use of solely the individual memory as the features of these crimes are very similar to typical "business issues". And even the victim may not always be completely sure if he/she has suffered from the fraudsters' manipulations or just fell under unfavourable market conditions or his/her own inappropriate behaviour.

Use of data fixed in documents to detect economic crimes, identify the circumstances leading to its commission with relevant proving significance is an important element of specific investigative techniques (Danshyn, 2005; Danshyn, Pavlov, 2011; Danshyn, Pohoretskyi, 2004). Accordingly, accounting, bank, and other documents don't contain any external features of crime commission fact but they do fix performance of certain business and financial activities, which are circumstances leading to the abovementioned crime commission - therefore, these operations are subject to thorough study by the experts. That is why the importance of documents as traces of economic crimes conditions the use of relevant methods in the course of the investigation - due detection, preserving and examination of documents with the use of operativesearch units' methodology, accounting procedures, economic analysis. It requires proper organization and coordination of interaction between investigators, operative staff, and regulatory agencies specialists.

\section{Features of economic crime commission investigation obstructing means}

This element of criminalistic characteristics is important for identification of methods, which are applied during the investigation of economic crimes by the units of law enforcement structures and regulatory agencies. There are numerous ways to commit the economic crimes - its selection depends strongly on the type of business activity and means applied. But there is one "typical" method related to economic crimes (taking into account its nature and use of business activity subjects) - application of payment transaction mechanism (appropriation of financial assets own by other persons and "transfer" of stolen money via bank accounts of enterprises under cover of sham contracts.

Criminalistic sources present several classifications of typical actions taken by the perpetrators who intend to steal one's property. But in our opinion, the most informative is the approach, which is based on use of payment transaction mechanism peculiarities: 1) use of computers and other electronic devices to complete sham electronic transactions; 2) conclusion of sham contract under the condition of advance payment with the following appropriation of partner's financial assets; 3) establishment of investment enterprise (accredited enterprise, pension fund, insurance company etc.) with the following appropriation of depositors' financial assets; 4) launching and use of sham cashless payment means in the course of business activity; 5) fraudulent scheme for obtaining and appropriation of credit (Volobuiev, 2000).

The abovementioned ways of economic crime commission always relate to specific traces - that is why its detection requires the use of methods based on special knowledge (economy, accounting, banking procedures, IT etc.) obtained by experts and specialists of state regulatory agencies. But detection of traces (features) characterizing certain ways also requires consideration of potential resistance and obstructing the law enforcement and regulatory agencies activities. Analysis of specialized literature dedicated to problems of investigation obstructing and its elimination allows distinguishing the following typical ways of obstructing, which condition use of certain methods including operative-search activity to neutralize it including the relevant forms of investigation organization:

1) Methods of investigation obstructing aimed at destruction, concealment or falsification of data:

- concealment, falsification, destruction of the document; witness manipulation;

- individuals cover-up in the course of the investigation; - evasion from the testimony submission (false testimony);

- the murder of key parties to the criminal proceeding.

2) Methods of investigation obstructing aimed at the establishment of unfavourable external conditions: disseminating negative information in the community related to crime investigation process; interference in crime investigation process by corrupted officials.

3) Methods of investigation obstructing aimed at the establishment of unfavourable internal conditions: obstructing the investigation by untimely organization of investigative-operative groups (IOG), regular and unjustified rotation of its members; disclosure of confidential data of the criminal case to third parties; direct interference into the investigative process by giving instructions, bringing certain proposals etc.; suspension of the most qualified, active, and impartial employees from the process.

4) Methods of investigation obstructing aimed directly at investigator (members of investigative-operative groups): 
bribery, threats (destruction of property, bodily injury, murder) and actual demonstration of mentioned threats.

\section{Conclusions}

To conclude the abovementioned, we should note that specific factors of fact-finding procedure in the course of pre-trial investigation and peculiarities of economic crime criminalistic characteristics substantially affect the nature and areas of law enforcement bodies' interaction during the pre-trial investigation of economic crimes as they determine specific tasks and methods of its accomplishment. Still, it must be stressed that criminalistic analysis of the aforesaid processes directly relates to more important issues - strengthening the potential of our country as a democratic state with the tight connection of its economic interests efficient protection and rule of law prioritization in all (Golovko, Kahanovska, 2017).

\section{References:}

Pavlenko S. (2017). Training for police staff in the course of MIA of Ukraine system reforming in line with EU standards. Molodyi vchenyi, № 4, pp. 331-336.

Luzgin I. (1969). Investigation as a fact-finding process: textbook. M.: Higher School of MIA of USSR, 178 p.

Volobuiev A., Danshyn M., Ishchenko A. etc. (2017). Forensic science: textbook: in 2 vol. Vol. 1; edited by A. Volobuiev, R. Stepaniuk, V. Maliarova; MIA of Ukraine, Kharkiv, National University of Internal Affairs. Kharkiv, $384 \mathrm{p}$.

Tsilmak O., Korystin O., Zayets O. etc. (2017). Modern methodology of pre-trial investigation (criminal offences): textbook / Edited by O. Tsilmak. Odesa, Phoenix, 352 p.

Volobuiev A. (2003). Economic crimes: definitions and problems of investigation methodology. Current problems of state and law. Collection of scientific papers. Odesa: Yurydychna literatura, pp. 35-39.

Matusovskyi H. (1999). Economic crimes: criminalistic analysis. Kharkiv: Konsum, 480 p.

Cherniavskyi S. (2009). Subject of crimes related to business activity. Journal of National University of State Tax Service of Ukraine. № 4, pp. 258-266.

Volobuiev A. (2000). Problematic issues of methodology of investigating property embezzlement in business area: [monograph]. Kharkiv, $335 \mathrm{p}$.

Sevruk V. (2016). Organized groups and criminal organizations formed on basis of ethnic origin: current problems. Counteracting terrorism, separatism, extremism and illegal migration in current conditions: international scientificpractical conference. Dnipro : Dnipropetrovsk State University of Internal Affairs, pp. 135-136.

Cherniavskyi S. (2010). Economic fraud: methodological background of investigation: [monograph]. "High-Tech Press", 624 p.

Danshyn M. (2005). Criminalistic characteristics of office abuse in economic area: means of concealment. Prevention of office abuse in economic area: international scientific-practical conference. Kyiv, Yurinkom Inter, pp. 174-177.

Danshyn M., Pavlov O. (2011). Current issues of criminal assets legalization (money laundering): Israeli experience. Latest achievements in science and education: materials of $V$ international conference (September 27 - October 4, 2011, Netanya, Israel). Khmelnytskyi, Khmelnytskyi National University, vol. 2, pp. 163-166.

Danshyn M., Pohoretskyi M. (2004). Detection of specific features of smuggled goods concealment: criminalistic and operative aspects. Journal of Zaporizhia Institute of MIA of Ukraine, № 1, pp. 189-195.

Golovko O., Kahanovska T. (2017). Reformation ideas, state and law. Journal of V. Karazin Kharkiv National University, section “Law", vol. № 24, pp. 6-11. 